\title{
SPACE VECTOR PWM TECHNIQUE FOR THREE- TO SEVEN-PHASE AC-TO-AC POWER CONVERTERS: ANALYSIS AND EXPERIMENTAL VERIFICATIONS
}

\author{
Sherif M. Dabour, S. M. Allam , Essam M. Rashad \\ Department of Electrical Power and Machines Engineering, Tanta University, Egypt
}

\begin{abstract}
This paper presents Pulse Width Modulation (PWM) control technique for three to seven-phase acto-ac power converters. These proposed PWM techniques are based on Indirect Space Vector Modulation (ISVM), which model the converter as two independent stages perform rectification and inversion stages. Two schemes of ISVM are proposed. The first scheme maximizes the voltage transfer ratio (VTR) of the converter but it produces unwanted low order harmonics. The second scheme generates sinusoidal output voltage waveforms; the cost is a reduction in the VTR of this configuration in linear mode. The viability of the proposed technique is proved using experimental results.
\end{abstract}

Keywords : Seven-phase, ac-to-ac converter, matrix converter, space vector modulation, PWM

\section{Introduction}

The application of power electronics converters in electric drives enables utilization of multiphase AC motors with a phase number higher than three. Such motor drives are nowadays considered for various applications due to their several advantages [1]-[3]. These advantages are inherent to the own structure of the machine, such as reducing the amplitude and increasing the frequency of torque pulsations and reducing the rotor harmonic current losses [4].The multiphase power converters delivered the required power to such motors. A two-level or multilevel multiphase inverter is the standard solution [5]-[8]. However it has the disadvantage of needing large storage elements. This disadvantage is avoided by using the direct ac-to-ac converter. This converter is called Matrix Converter (MC).The $\mathrm{MC}$ is a direct m-phase to n-phase converter, was firstly investigated as a direct three- to three-phase converter in [9] and it steadily growth, pushed by the progress of the power electronics technology.After almost three decades of intensive research, the development of $\mathrm{MC}$ has been involved in industrial applications. The most common configuration of the MC discussed in the literature is the three- to three-phase, little attention has been aid on the development of MC with output more than three, such as [10]-[14].

This paper concerns with seven-phase MC. It is connects the three-phase power supply with the seven-phase load directly. The advantages of this converter, when compared with the standard seven-phase VSI are the absence of dc-link, sinusoidal input and output currents, possible power factor control, four-quadrant operation, compact design, regeneration capability and it has no limit on output frequency. However, its disadvantages are reduced maximum VTR, many switches needed, increased complexity of control and sensitivity to input voltage disturbances. These drawbacks are the same for three-phase MC, there are many published research work to solve such problems [15]-[16] and it can be extended to seven-phase MC. In all, the progress of MC has 
significantly improved its performance, rendering it an acceptable choice for compact and integrated converter-motor drives.

This paper proposes two SVPWM schemes of the seven-phase converter based on the direct and indirect modulation. The direct SVM utilizes 2187 permitted switching combinations; it is classified into eight groups. However, 1011switching vectors are suitable for the implementation. The indirect SVM also presented. It is based on the indirect equivalent topology of the direct $3 \times 7$ phase MC, which model the converter as a three-phase rectifier followed by a seven-phase inverter. Both of the two stages are space vector modulated. Two SVPWM schemes of the inverter stage are introduced; one by considering only the outermost (two active) space vectors and the second is considering six-active space vectors in each sector. The maximum voltage transfer ratio (VTR) of this converter is 0.939 in linear mode using large space vectors only in the inverter stage. While, the output phase voltages and currents contain a consider amount of third and fifth harmonics. Sinusoidal output voltages and current are generated in use of six-active vector in the inverter stage. The cost is a reduced VTR. It reduces to 0.7694 . The modulation technique has been implemented using Simulink. Then, the algorithm is compiled to real time system based on DS1104 dSPACE GmbH card. The generated signals from the card are applied to the implemented switching matrix through an interface circuit. Finally, the experimental results are presented and discussed.

\section{Seven-Phase Matrix Converter Topology}

The seven-phase MC utilizes $21^{\text {th }}$ switches, as shown in Fig. 1. Each of the switches depicted is a bidirectional switch (BDS), which are connected so that, any of the input phases (A, B \& C) can be connected to any of the output phases; ( $a, b, c$... and g) for a given switching. The output voltages $\left(v_{a}\right.$ to $\left.v_{g}\right)$ are therefore derived directly from the input voltages $\left(v_{A} \operatorname{tov}_{C}\right)$ using the modulation matrix of the switches, $S$ as follows:

$$
\left[\begin{array}{lllllll}
\mathrm{v}_{\mathrm{a}} & \mathrm{v}_{\mathrm{b}} & \mathrm{v}_{\mathrm{c}} & \mathrm{v}_{\mathrm{d}} & \mathrm{v}_{\mathrm{e}} & \mathrm{v}_{\mathrm{f}} & \mathrm{v}_{\mathrm{g}}
\end{array}\right]^{\mathrm{T}}=[\mathrm{S}]\left[\begin{array}{lll}
\mathrm{v}_{\mathrm{A}} & \mathrm{v}_{\mathrm{B}} & \mathrm{v}_{\mathrm{C}}
\end{array}\right]^{\mathrm{T}}
$$

On the other hand, the relation between the three-phase input currents and the seven-phase output currents can be written as:

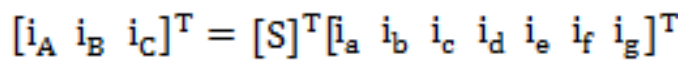

where $\mathrm{S}$ represents the switching states modulation matrix which can be written as:

$$
[S]=\left[\begin{array}{lll}
S_{a A} & S_{a B} & S_{a C} \\
S_{b A} & S_{b B} & S_{b C} \\
S_{c A} & S_{c B} & S_{c C} \\
S_{d A} & S_{d B} & S_{d C} \\
S_{e A} & S_{a B} & S_{a C} \\
S_{f A} & S_{f B} & S_{f C} \\
S_{g A} & S_{g B} & S_{g C}
\end{array}\right]
$$




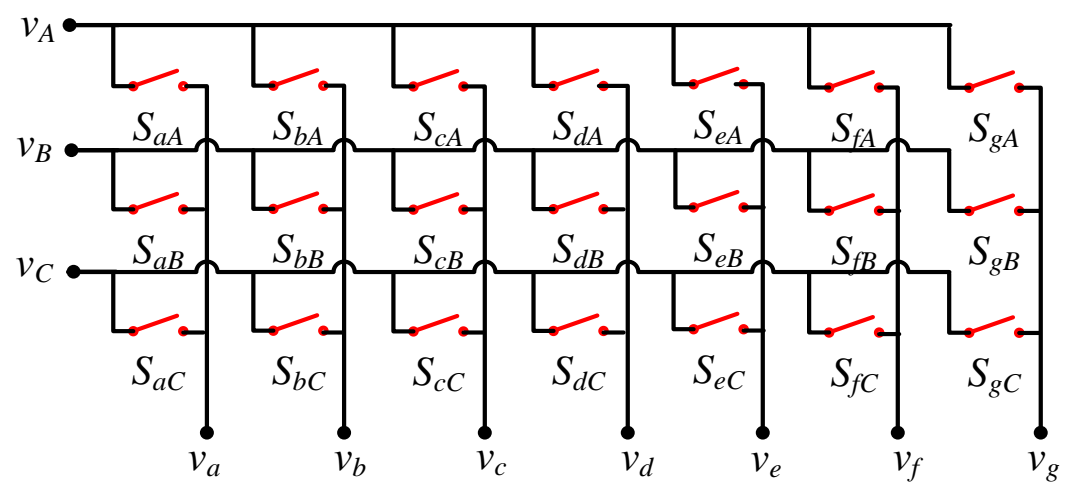

Fig. 1 The topology of $3 \times 7 \mathrm{MC}$

\section{Space Vector Modulation Algorithm}

The SVM technique constructs the desired sinusoidal output voltage by selecting the valid switching states of the converter and calculating their corresponding durations. In this paper the SVM techniques for controlling the $3 \times 7 \mathrm{MC}$ are classified into Direct Space Vector Modulation (DSVM) and Indirect Space Vector Modulation (ISVM). In the next sub-sections; only the valid switching combinations of DSVM scheme are presented. However, the detailed analysis and implementation of ISVM scheme are introduced.

\section{A. DirectSpace Vector Modulation}

With the $21^{\text {th }}$ BDS, the MC has $2^{21}(2,097,152)$ different switching states. Some of the basic rules must be regarded at any switching time. These rules are: input phases must never be shorted and output phases must not be left open, due to the inductive nature of the load. Observing these rules, the states reduce to $3^{7}$ (2187) different switching combinations. These switching combinations can be classified into eight groups. The switching combinations are represented as $\{\mathrm{P}, \mathrm{Q}, \mathrm{R}\}$, where $\mathrm{P}, \mathrm{Q}$, and $\mathrm{R}$ represent the number of output phases connected to input phases $\mathrm{A}$, $\mathrm{B}$, and $\mathrm{C}$, respectively.

Group 1:All of the output phases are connected to the same input phase (A or B or C). This group consists of three possible switching combinations. $\{7,0,0\}$ represents the switching conditions when all of the output phases connect to input phase A. $\{0,7,0\}$ represents the switching conditions when all of the output phases connect to input phase B. $\{0,0,7\}$ represents the switching conditions when all of the output phases connect to input phase $\mathrm{C}$. These vectors have zero magnitude and are called zero vectors.

Group2: Six of the output phases are connected to the same input phase, and the seventh is connected to any of the other two input phases. In this manner, there exist six different switching states $(\{6,1,0\},\{1,6,0\},\{1,0,6\},\{0,1,6\},\{0,6,1\}$, and $\{6,0,1\})$. Out of these, one switching state can have further seven different combinations. This group hence consists of $6 \times 7=42$ switching combinations in all. These vectors have variable amplitude at a constant frequency.

Group 3: Five of the output phases are connected to the same input phase, and the two other output phases are connected to any of the other two input phases. As such, there exist six different switching states $(\{5,2,0\},\{2,5,0\},\{2,0,5\},\{0,2,5\},\{0,5,2\}$, and $\{5,0$, $2\})$. Out of these, one switching permutation can have further twenty-one different 
combinations. This group hence consists of $6 \times 21=126$ switching combinations. These vectors also have variable amplitude at a constant frequency in space.

Group 4: Four of the output phases are connected to the same input phase, and the three other output phases are connected to any of the other two input phases. As such, there exist six different switching states $(\{4,3,0\},\{3,4,0\},\{3,0,4\},\{0,3,4\},\{0,4,3\}$, and $\{4,0$, $3\})$. Out of these, one switching permutation can have further thirty-five different combinations. This group hence consists of $6 \times 35=210$ switching combinations. These vectors also have variable amplitude at a constant frequency in space.

Group 5:Four of the output phases are connected to the same input phase. Moreover, two of the output phases are connected to the other input phase and the remaining output phase is connected to the remaining input phase. As such, there exist six different switching states $(\{4,2,1\},\{2,4,1\},\{2,1,4\},\{1,2,4\},\{1,4,2\}$, and $\{4,1,2\})$. Out of these, each switching state can have further 105 different combinations. This group hence consists of $6 \times 105=630$ switching combinations. These vectors have variable-amplitude variable frequency in space.

Group 6:Five of the output phases are connected to the same input phase, and the two other output phases are connected to the other two input phases, respectively. As such, there exist three different switching states $(\{5,1,1\},\{1,5,1\}$, and $\{1,1,5\})$. Out of these, each switching state can have further 42 different combinations. This group hence consists of $3 \times$ $42=126$ switching combinations. These vectors have variable-amplitude variable frequency in space.

Group 7:Three of the output phases are connected to the same input phase, and the other three output phases are connected to the other input phase. Moreover, the remaining output phase is connected to the other input phase. As such, there exist three different switching states $(\{3,3,1\},\{3,1,3\}$, and $\{1,3,3\})$. Out of these, each switching state can have further 140 different combinations. This group hence consists of $3 \times 140=420$ switching combinations. These vectors have variable-amplitude variable frequency in space.

Group 8:Three of the output phases are connected to the same input phase, and the other two output phases are connected to the other input phase. Moreover, the remaining two output phases are connected to the other input phase. As such, there exist three different switching states $(\{3,2,2\},\{2,2,3\}$, and $\{2,3,2\})$. Out of these, each switching state can have further 210 different combinations. This group hence consists of $3 \times 210=630$ switching combinations. These vectors have variable-amplitude variable frequency in space.

There are 2187 permitted switching combinations of the three-phase to seven-phase matrix converter. However, in the proposed SVPWM strategy the switching vectors used for the SVPWM technique are 1011. Only the switching states of groups 1,2, 3, 4 and 5 have been utilized and it can divided into the following:

Group 1: $\{7,0,0\}$ consists of 3 vectors.

Group 2: $\{6,1,0\}$ consists of 42 vectors.

Group 3: $\{5,2,0\}$ consists of 126 vectors.

Group 4: $\{4,3,0\}$ consists of 210 vectors.

Group 5: $\{4,2,1\}$ consists of 630 vectors.

The digital implementation of this technique is difficult due to large number of the resulting switching vectors. To avoid this difficulty, the indirect SVM (ISVM) technique has been used. This technique is based on the indirect modulation of the MC and was firstly proposed in [17] for threeto three-phase MC and extended to three- to five-phase MC in [10]-[11]. In the following, this technique has been applied to the three- to seven-phase MC. 


\section{B. Indirect Space Vector Modulation}

This method to control the seven-phase MC actually corresponds to regard it as a combination of virtual rectifier and inverter stages without any DC-Link as shown in Fig. 2. The rectifier stage has the same topology of a three-phase rectifier with six switches $\left(\mathrm{S}_{1}-\mathrm{S}_{6}\right)$, and the Inverter stage has a standard seven-phase VSI topology consisting of fourteen switches $\left(\mathbf{S}_{7}-\mathbf{S}_{20}\right)$. The basic idea of this technique is to decouple the control of the input current (control of rectifier stage) and the control of output voltage (control of inverter stage). This is done by splitting the modulation matrix, $\mathrm{S}$ for the converter into the product of a rectifier transfer function, $R$ and an inverter transfer function, $I$ as follows;

$$
S=I \cdot R
$$

$$
\left[\begin{array}{lll}
S_{a A} & S_{a B} & S_{a C} \\
S_{b A} & S_{b B} & S_{b C} \\
S_{c A} & S_{c B} & S_{c C} \\
S_{d A} & S_{d B} & S_{d C} \\
S_{e A} & S_{e B} & S_{e C} \\
S_{f A} & S_{f B} & S_{f C} \\
S_{g A} & S_{g B} & S_{g C}
\end{array}\right]=\left[\begin{array}{ll}
s_{7} & s_{8} \\
s_{9} & s_{10} \\
s_{11} & s_{12} \\
s_{13} & s_{14} \\
s_{15} & s_{16} \\
s_{17} & s_{18} \\
s_{19} & s_{20}
\end{array}\right] \times\left[\begin{array}{lll}
s_{1} & s_{3} & s_{5} \\
s_{2} & s_{4} & s_{6}
\end{array}\right]
$$

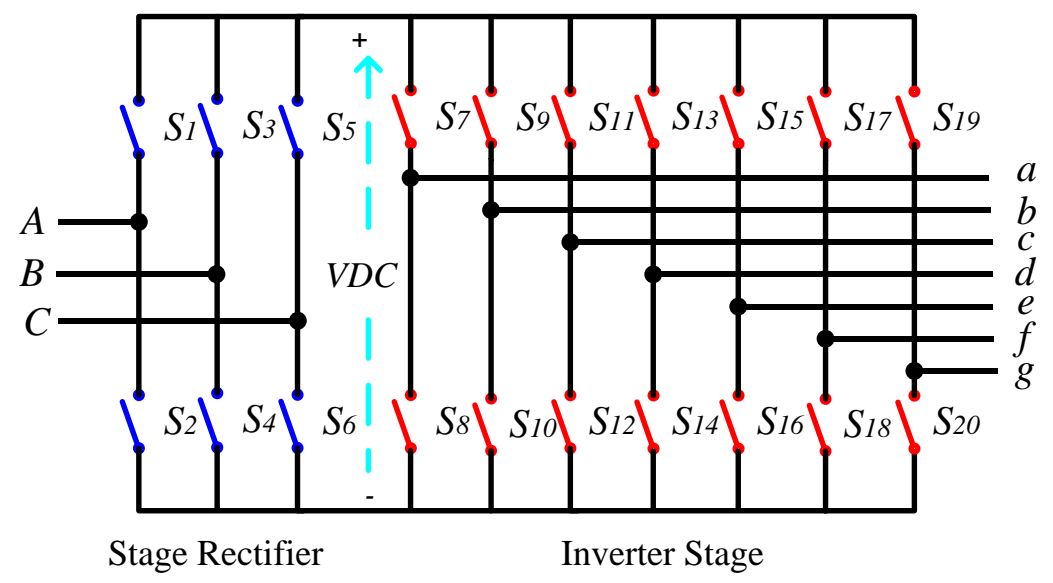

Fig. 2 Indirect equivalent model of Seven-Phase MC

\section{1. $\quad$ Space Vector Rectifier (SVR):}

The rectifier switchescan have only possible nine allowed combinations (active vectors, $I_{1}-I_{6}$ and zero vectors, $\left.I_{7}-I_{9}\right)$ as represented in Fig. 3 [18]. The reference input current vector $\left(I_{i}^{*}\right)$ is synthesized by impressing the adjacent switching vectors $I_{\gamma}$ and $I_{\delta}$ with the duty cycles $d_{\gamma}$ and $d_{\delta}$, respectively as follows;

$$
I_{\text {in }}^{*}=d_{\gamma} \cdot I_{\gamma}+d_{\delta} \cdot I_{\delta}+d_{o c} \cdot I_{\circ}
$$

Thus, the duty cycles are written as;

$$
d_{y}=m_{c^{*}} \sin \left(\pi / 3-\theta_{c}\right)
$$




$$
d_{\delta}=m_{c} \cdot \sin \left(\theta_{c}\right)
$$

The duration of the zero-vector is calculated by;

$$
d_{o c}=1-\left(d_{y}+d_{\delta}\right)
$$

where, $\theta_{C}$ indicates the angle of reference current vector within the actual hexagon sector, $m_{C}$ is the current modulation index and defines the desired current transfer ratio such as;

$$
0 \leq m_{c} \leq 1 \quad \& m_{C}=I_{\text {in }}^{*} / I_{p}
$$

The virtual average DC-link voltage $\left(V_{D C}\right)$ is calculated by using the fact that there are no reactive elements in the MC. This means, the input power flow, the virtual DC power flow and the output power flow are equal at any instant. Therefore, the $\mathrm{V}_{\mathrm{DC}}$ expression as a function of peak input phase-voltage $\left(\hat{V}_{I N}\right), m_{c}$ and input current displacement angle $\left(\varphi_{i n}\right)$ is;

$$
V_{D C}=3 / 2 \hat{V}_{I N} m_{c} \cos \left(\varphi_{i n}\right)
$$

\section{Space Vector Inverter (SVI)}

SVM techniques in the standard seven-phase inverter are reported in many researcher works such as [19-22]. However, it has reproduced here to modulate the inverter stage of the indirect equivalent model of a seven-phase MC.

The seven-phase inverter switches have only $128\left(2^{7}\right)$ allowed switching states. These states produce 126 active voltage vectors $\left(V_{1}\right.$ to $\left.V_{126}\right)$ and two zero vector $V_{z}\left(V_{0}\right.$ and $\left.V_{127}\right)$ as represented in the fourteen sided polygons (tetra-decagon) of Fig. 4 [22].

The voltage vectors shown have eight levels. While, the space vectors plane can be divided into 14 sectors (each spanning $\pi / 7$ ). The reference voltage vector $\left(V_{r}^{*}\right)$ is synthesized by impressing the adjacent voltage vectors $V_{\alpha}, V_{\beta}$ and $V_{z}$ with the duty cycles $d_{\alpha}, d_{\beta}$ and $d_{0 v}$ respectively as follows;

$$
V_{r}^{*}=d_{\alpha^{*}}, V_{\alpha}+d_{\beta} \cdot V_{\beta}+d_{o v}, V_{z}
$$

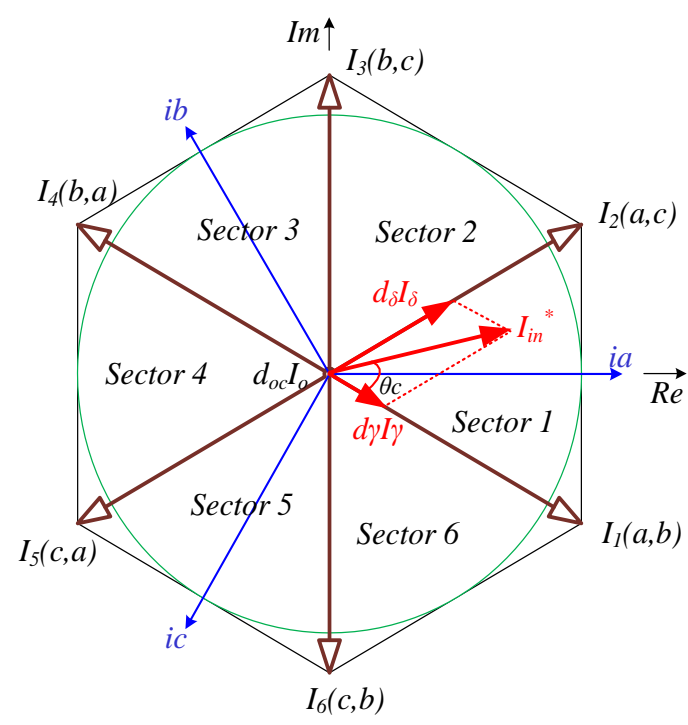

Fig. 3 Rectifier current hexagon 


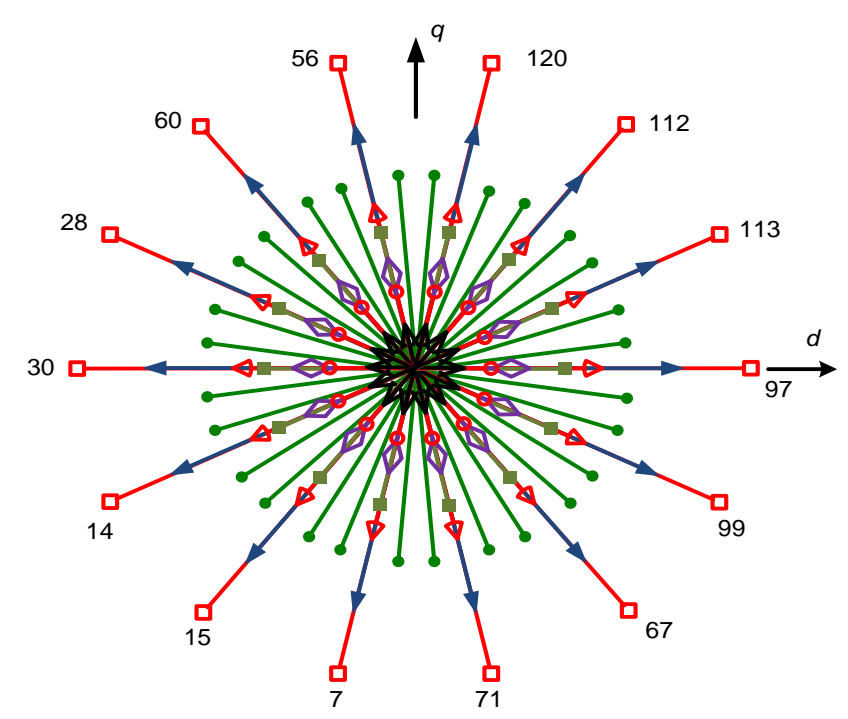

Fig. 4 The tetra-decagonof inverter stage

Assuming that, only space vectors with the largest magnitude are involved in the PWM pattern (Fig. 5).

Such an approach, used on [10] for a five-phase MC. Thus, the duty cycles in sector 1 are defined as;

$$
\begin{aligned}
& d_{\alpha}=m_{v^{\prime}} \sin \left(\pi / 7-\theta_{v}\right) \\
& d_{\beta}=m_{v^{\prime}} \sin \left(\theta_{v}\right)
\end{aligned}
$$

The duration of the zero-vector is calculated by;

$$
d_{o v}=1-\left(d_{\alpha}+d_{\beta}\right)
$$

where, $\theta_{v}$ indicates the angle of reference voltage vector within the actual tetra-decagon sector, $m_{v}$ defines the desired voltage modulation index such as;

$$
m_{v}=V_{r}^{*} /\left[V_{l} \sin (\pi / 7)\right]
$$

where $v_{l}=0.642 \mathrm{~V}_{\mathrm{dc}}$ represents magnitude of the largest space vectors. From the inverter stage tetra-decagon of Fig. 4, the maximum allowable length of reference vector $V_{r}{ }^{*}$ which provides linear modulation (circle inscribed in tetra-decagon $\left(m_{v} \leq 2.247\right)$ ) is equal to;

$$
V_{r_{2} \max }^{*}=V_{l} \cos (\pi / 14)=0.6259 V_{D C}
$$

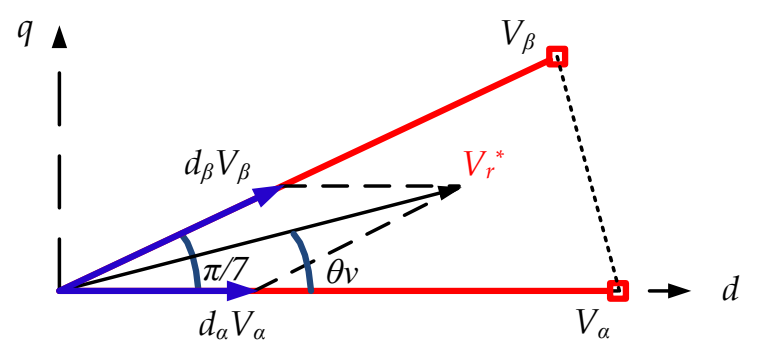

Fig. 5 Only space vectors with the largest magnitude are involved in sector 1 
However, the maximum peak fundamental output in fourteen-step operation mode is $2 / \pi V_{D C}$. Thus, the ratio of the maximum possible fundamental output voltage with SVM using large vectors and in fourteen-step mode is $98.3 \%$. The switching pattern for sector 1 is illustrated in Fig. 6, showing seven leg voltages. It is important to note that the three legs ( $a, b$ and $g$ ) have same pattern and three other legs (d, e and f) have same pattern. In other word, it can be said that these legs are turned off simultaneously. The output voltage generated by this method contains a significant amount of lower order harmonic especially third and fifth [22].

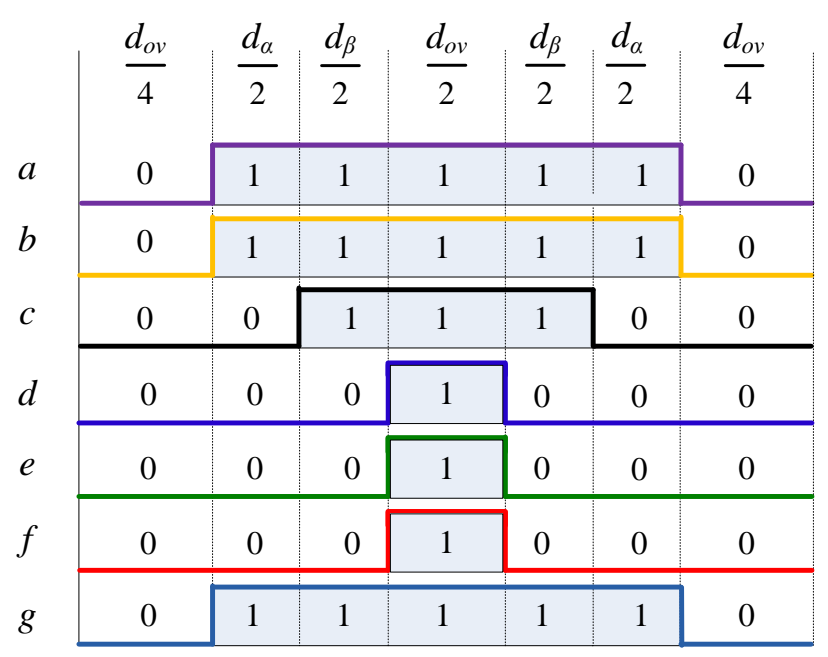

Fig. 6 Switching pattern related to sector 1 for SVPWM with large space vectors only

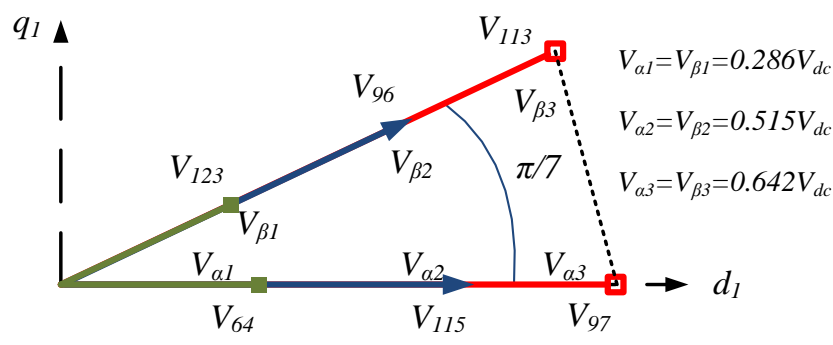

Fig. 7 Principle of calculation of times of application of active space vectors

To provide symmetrical PWM pattern with single commutation in each inverter leg over the switching period, starting from (0000000) up to (1111111) and vice versa, six active space-vectors ( $\mathrm{n}-1$ vectors, $\mathrm{n}$ is the number of phases) are selected in each sector [19] (Fig. 7). Calculated duty cycles of space vectors $v_{\alpha}$ and $v_{\beta}$ must be properly distributed among active space vectors, satisfying constraints given with;

$$
\begin{aligned}
& d_{\alpha}=d_{\alpha 1}+d_{\alpha 2}+d_{\alpha 3} \\
& d_{\beta}=d_{\beta 1}+d_{\beta 2}+d_{\beta 3}
\end{aligned}
$$

Different schemes are used to determine the duty cycles of each vector. Here, a proportional subdivision of switching times method is applied. This method is based on the subdivision of total time into times for application of the selected space vectors as follows; 


$$
\begin{aligned}
& d_{\alpha 1}=d_{\alpha}\left|v_{\alpha 1}\right| /\left(\left|v_{\alpha 1}\right|+\left|v_{\alpha 2}\right|+\left|v_{\alpha 3}\right|\right) \\
& d_{\alpha 2}=d_{\alpha}\left|v_{\alpha 2}\right| /\left(\left|v_{\alpha 1}\right|+\left|v_{\alpha 2}\right|+\left|v_{\alpha 3}\right|\right) \\
& d_{\alpha 3}=d_{\alpha}\left|v_{\alpha 3}\right| /\left(\left|v_{\alpha 1}\right|+\left|v_{\alpha 2}\right|+\left|v_{\alpha 3}\right|\right) \\
& d_{\beta 1}=d_{\beta}\left|v_{\beta 1}\right| /\left(\left|v_{\beta 1}\right|+\left|v_{\beta 2}\right|+\left|v_{\beta 3}\right|\right) \\
& d_{\beta 2}=d_{\beta}\left|v_{\beta 2}\right| /\left(\left|v_{\beta 1}\right|+\left|v_{\beta 2}\right|+\left|v_{\beta 3}\right|\right) \\
& d_{\beta 3}=d_{\beta}\left|v_{\beta 3}\right| /\left(\left|v_{\beta 1}\right|+\left|v_{\beta 2}\right|+\left|v_{\beta 3}\right|\right)
\end{aligned}
$$

This yield;

$$
\begin{aligned}
& d_{\alpha 1} / d_{\alpha}=d_{\beta 1} / d_{\beta}=0.198 \\
& d_{\alpha 2} / d_{\alpha}=d_{\beta 2} / d_{\beta}=0.357 \\
& d_{\alpha 3} / d_{\alpha}=d_{\beta 3} / d_{\beta}=0.445
\end{aligned}
$$

The duty ratio of zero vectors is now given as;

$$
d_{o v}=1-\left(d_{\alpha 1}+d_{\alpha 2}+d_{\alpha 3}+d_{\beta 1}+d_{\beta 2}+d_{\beta 3}\right)
$$

Owing to the above sub-division, the reference voltage vector in sector 1 is synthesized by impressing the adjacent voltage vectors and $V_{z}$ with the duty cycles in (16)-(17) as follows;

$$
V_{r}^{*}=\sum_{i=1}^{3}\left(d_{\alpha i}, V_{\alpha i}+d_{\beta i}, V_{\beta i} e^{j \frac{\pi}{\eta}}\right)+d_{o v} \cdot V_{z}
$$

After substituting the duty ratios expressions (15)-(17) into (18), the output phase voltage $\left(V_{o}^{*}\right)$ of the inverter stage is;

$$
V_{o}^{*}=V_{r}^{*} \frac{0.5262}{V_{l} \sin \left(\frac{\pi}{7}\right)}\left\{\sin \left(\frac{\pi}{7}-\theta_{v}\right)+\sin \left(\theta_{v}\right) e^{j \frac{\pi}{7}}\right\} e^{j \omega t}
$$

The aforementioned expression indicates that the maximum output fundamental phase voltage $\left(\left|V_{o}^{*}\right|\right.$ at $\left.\theta_{v}=\pi / 14\right)$ only $81.96 \%$ of the input reference voltage value $\left(V_{r}^{*}\right)$. From (13), the maximum achievable output fundamental voltage can be obtained from the following;

$$
V_{o_{0} \max }^{*}=0.8196 \times V_{l} \cos (\pi / 14)=0.513 V_{D C}
$$

The ratio of the maximum fundamental using large space vector only to that using six active vectors is $122 \%$. Thus, the reference voltage magnitude has to be scaled with the factor $1 / 0.8196=$ 1.22 in order to get the desired fundamental at the output. The switching pattern for sector 1 using this method is illustrated in Fig. 8. 


\section{Maximum VTR of the Seven-phase Matrix Converter}

Based on the indirect modulation, there are two VTRs to be controlled in the matrix converter; the inverter side VTR, $M_{I}\left(V_{o_{2} \max }^{*} / V_{D C}\right)$ and the rectifier side VTR, $M_{R}\left(V_{D C} / \widehat{V}_{I N}\right)$. The VTR of the

$$
\begin{aligned}
& \text { MC, } M \text { is the product of these VTRs; } \\
& M=M_{R} \times M_{I}
\end{aligned}
$$

In the case of using two-active space vectors in controlling the inverter side, the maximum obtainable VTR is 0.939 for unity input displacement factor and unity input current modulation index. While, In the case of using six-active space vectors, the maximum obtainable VTR is 0.7695 .

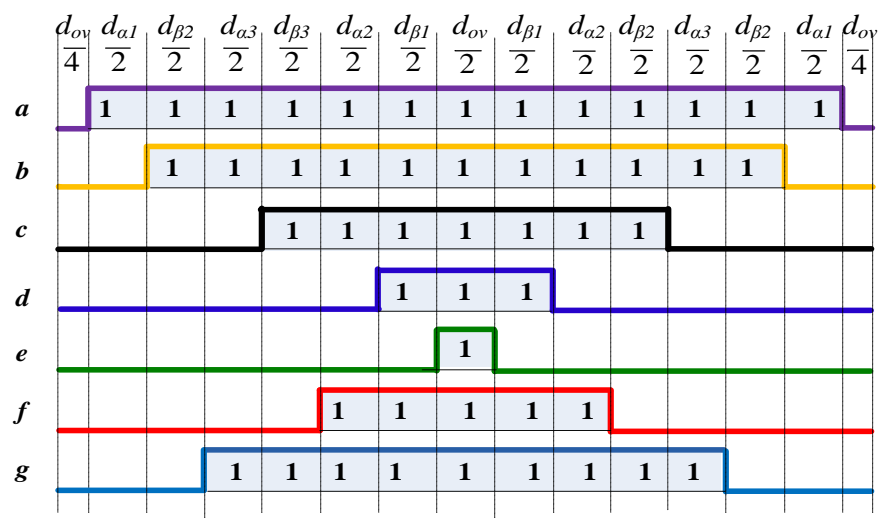

Fig.8 switching pattern related to sector 1 for SVPWM with six active vectors

\section{Experimental Results}

To testify the converter behavior, the output phases (a-g) of the converter are connected to the passive load $(144 \Omega$ and $0.25 \mathrm{H})$. A small input voltage supply of $100 \mathrm{Volts} /$ line at $50 \mathrm{~Hz}$ is applied. The reference input current displacement angle adjusted to zero, which achieves maximum available VTR of the converter. The switching frequency is $1 \mathrm{kHz}$ and the sampling time is $200 \mu \mathrm{sec}$ due to the controller capability.

Fig. 9 describes the experimental results of output line voltages waveforms at $20 \mathrm{~Hz}$ and its spectrum. It is clear to see that, the phase angle between the two voltages is $2 \pi / 7$.

However, Fig. 10 shows the experimental results of the load currents waveforms and its spectrum analysis. shows the supply voltage and unfiltered input current waveforms. It is clear that, the fundamental component of the input current is approximately in phase with the input phase voltage. This is owed to adjusting displacement angle to zero.The experimental results prove the viability of the proposed SVPWM technique for the seven-phase MC. 

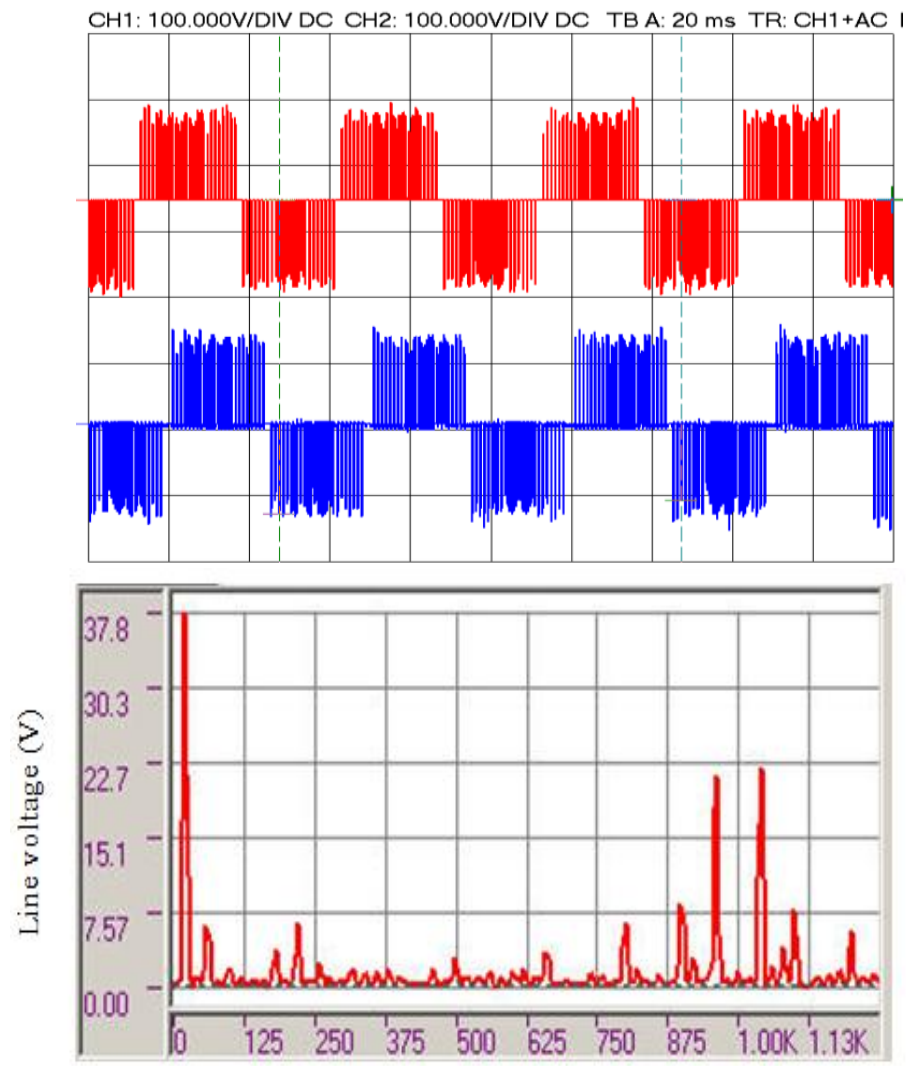

Fig. 9 Output voltages waveforms at $f_{o}=20 \mathrm{~Hz}$. (Upper trace) line-voltages and (Bottom trace) its spectrum.
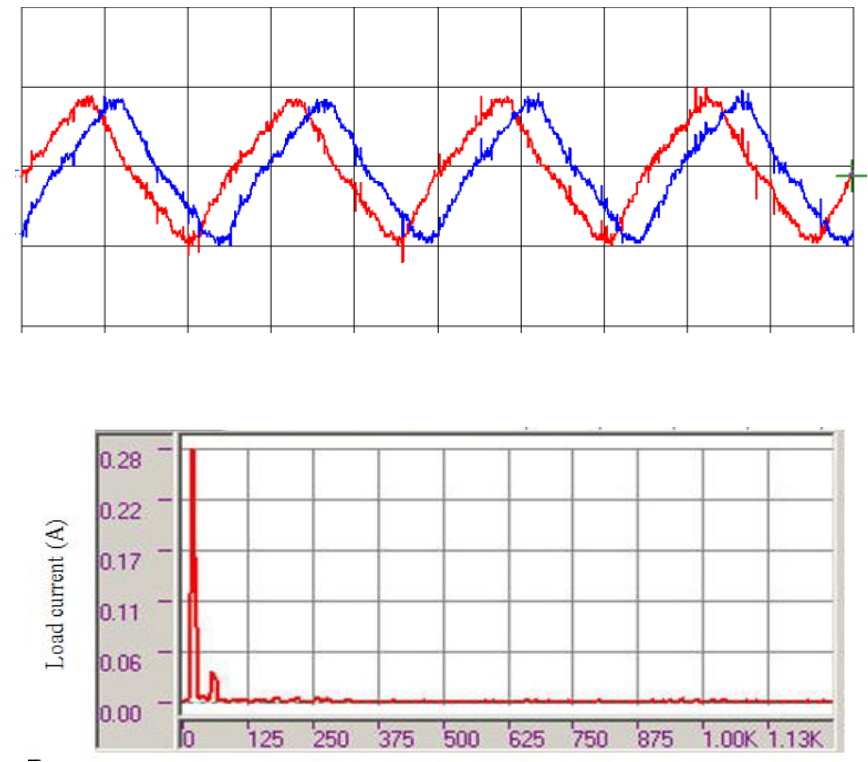

Fig. 10 Experimental results of load currents waveforms at $f_{o}=20 \mathrm{~Hz}$. 


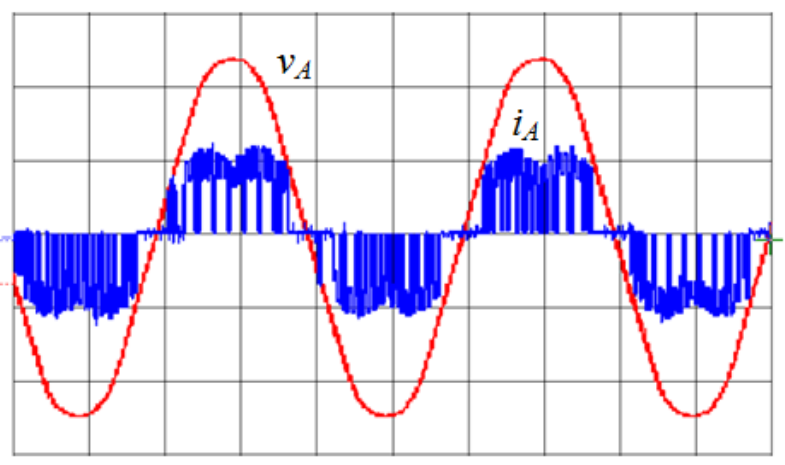

Fig. 11 Experimental results of input voltage and current waveforms.

\section{Conclusion}

This paper presents the SVM techniques to control the three-phase to seven-phase matrix converters. The switching vectors of the direct modulation are introduced and classified into eight groups. Five groups only are suggested to implement the direct space vector modulation. The indirect space vector modulation is proposed and implemented. Two SVM schemes of controlling the seven-phase inverter stage are introduced. One has two active vectors. The maximum obtainable voltage transfer ratio using this method is 0.939 for linear modulation. This scheme leads unwanted low order harmonic in the output voltages and currents. However, the second scheme generates sinusoidal output waveform. The voltage ratio of the converter is reduced to 0.7695. The converter prototype has been implemented using discrete semiconductors. The feasibility of the proposed technique has been verified through experiments.

\section{References}

[1] A. N. Golubev and S. V. Ignatenko, "Influence of number of stator winding phases on the noise characteristics of an asynchronous motor," Russ. Electr. Eng., vol. 71, no. 6, pp. 41-46, 2000

[2] E. Levi, R. Bojoi, F. Farina, H. A. Toliyat and S. Williamson, "Multi-phase induction motor drives-A technology status review,"IET Electr. Power Appl. Vol. 1, No. 4, pp. 489-516, 2007

[3] E. Levi, "Multi-phase electric machines for variable speed applications,"IEEE Trans. On Ind. Electronics, Vol. 55, No. 5, pp. 1893-1909, 2008

[4] S. Williamson and S. Smith, "Pulsating torques and losses in multiphase induction machines," IEEE Trans. Ind. Appl., vol. 39, no. 4, pp. 986-993 Jul./Aug. 2003

[5] E. Levi, M. Jones, S. N. Vukosavic and H. A. Toliyat, "A novel concept of a multiphase, multimotor vector controlled drive system supplied from a single voltage source inverter," IEEE Trans. Power Electron., vol. 19, no. 2, pp. 320-335, Mar. 2004

[6] A. Iqbal and S. K. Moinuddin, "Comprehensive relationship between carrier-based PWM and space vector PWM in a five-phase VSI,'IEEE Trans. Power Electron., vol. 24, no. 10, pp. 23792390, Oct. 2009

[7] J.-S. Hu, K.-Y. Chen, T.-Y. Shen and C.-H. Tang, "Analytical solutions of multilevel spacevector PWM for multiphase voltage source inverters," IEEE Trans. Power Electron., vol. 26, no.5, May 2011, pp. 1489-1502

[8] J. I. Leon, O. Lopez, L. G. Franquelo, J. Doval-Gandoy, S. Vazquez, J. Alvarez and F. D. Freijedo, "Multilevel multiphase feed-forward space vector modulation technique,"IEEE Trans. Ind. Electron., vol. 57, no. 6, pp. 2066-2075, Jun. 2010

[9] L. Gyugyi and B. R.Pelly, "Static Power Frequency Changers-Theory, Performance and Application,”New York: J. Wiley, 1976. 
[10] S. M. Dabour, A. wahab Hassan, E. M. Rashad, "Analysis and implementation of space vector modulated five-phase matrix converter," International Journal of Electrical Power \& Energy Systems Volume 63, December 2014, Pages 740-746

[11] A. Iqbal, M. Ahmed and H.Abu-Rub, "Space Vector PWM Technique for a Three-to-FivePhase Matrix Converter,'IEEE Transactions on Industry Applications, Vol. 48, No. 2, March/April 2012

[12] S. M. Ahmed, A. Iqbal, and H. Abu-Rub, "Generalized duty ratio based pulse width modulation technique for a three-to-k phase matrix converter,'IEEE Trans. Ind. Electron., vol. 58, no. 9, pp. 3925-3937, Sep. 2011

[13] S. M. Ahmed, A. Iqbal, and H. Abu-Rub, "Carrier-based PWM technique of a novel three-toseven-phase matrix converter,'Presented at the Int. Conf. Electrical Machine ICEM, Rome, Italy, Paper RF- 004 944, Sep, 3- 6, 2010

[14] S. M. Ahmed, A. Iqbal, H. Abu-Rub, , J. Rodriguez and C. Rojas, "Simple carrier-based PWM technique for a three to nine phase matrix converter,'IEEE Trans. Ind. Elect., vol. 58, no. 1, pp. 5014-5023, Nov. 2011

[15] O. Simon, J. Mahlein, M. N. Muenzer and M. Bruckmann, "Modern Solution for Industrial Matrix-Converter Applications,'IEEE Tran. Industrial Electronics, vol. 49, no. 2, pp. 401-406, Apr. 2002

[16] S. M. Dabour and E. M.Rashad, "Improvement of Voltage Transfer Ratio of Space Vector Modulated Three-Phase Matrix Converter,"Proc of the 15th International Middle East Power SystemsConference

(MEPCON'12), Egypt, Paper ID 232, pp. 581-586, December 2012

[17] L. Huber and D. Borojevic, "Space Vector Modulator for Forced Commutated Cycloconverters,"Proc. of PESC89, pp. 671-876, 1989

[18] S. M. Dabour and E. M.Rashad, "Analysis And Implementation of Space Vector Modulated Three-Phase Matrix Converter," IET Power Electronics, Volume 5, Issue 8, pp.1374-1378, September 2012

[19] G. Grandi, G. Serra, A. Tani, "Space vector modulation of a seven-phase voltage source inverter," Proc. Int. Symp. Power Electronics, Elec. Drives, Automation and Motion SPEEDAM, Taormina, Italy, 2006

[20] H. M. Ryu, J. H. Kim, S. K. Sul, "Analysis of multi-phase space vector pulse width modulation based on multiple d-q spaces concept," IEEE Trans. on Power Electronics, vol. 20, no. 6, pp. 1364-1371, 2005

[21] D. Dujic, E. Levi, M. Jones, G. Grandi, G. Serra, A. Tani, "Continuous PWM Techniques for Sinusoidal Voltage Generation with Seven-Phase Voltage Source Inverters," PESC 2007. IEEE, pp.47,52, 17-21 June 2007

[22] M. A. Khan, A. Iqbal, S. M. Ahmad, "Space Vector Pulse Width Modulation Scheme for a Seven-Phase Voltage Source Inverter," International Journal of Power Electronics and Drive System (IJPEDS) Vol.1, No.1, pp. 7-20, September 2011 